\title{
Translations of Georgian poet N. Baratashvili into Russian Language in the Aspect of Cross-Cultural Communication
}

\author{
Gogoladze Tamar Akhmedionowna ${ }^{1}$ \\ Professor, Gori State Teaching University, \\ Gori, Georgia. \\ (date of receiving: October, 2017; date of acceptance: August, 2018)
}

\begin{abstract}
Common fact that literary translation is a kind of literary process, which itself is the beginning of a new literary life and thinking, promotes cross-cultural communication, concerns creative translation of the Georgian romantic poet of the $19^{\text {th }}$ century Nikoloz Baratashvili (1817-1845) on various languages. The translations of N. Baratashvili were not published during the poet's life. The process of translating his works becomes more active especially after the 1920 s of the last century. Baratashvills works were translated into Russian both by Georgian and Russian poets and translators: V. Gaprindashvili, B. Pasternak, G.Tsagareli, M. Dudin and others. All-Union competition, announced in 1966, gave possibility to poets and literary critics of various nationalities to introduce the Georgian masterpiece, "Merani," to foreign readers relying on the Russian translation. Our article highlights some Russian translations of the works of N. Baratashvili, which is still great importance in the development of intercultural communication.
\end{abstract}

Keywords: Translations of Poetry, Common Fact, N. Baratashvili, Russian Translation, Literary Life.

1. E-mail: Tamilagogoladze@gmail.com 


\title{
Переводы поэзии грузинского поэта Н. Бараташвили на русский язык в аспекте межкультурных коммуникаций
}

Гоголадзе Тамар Ахмедионовна ${ }^{1}$

Профессор, Горийский государственный университет, Гори, Грузия.

(дата получения: октябрь 2017 г.; дата принятия: август 2018 г.)

\begin{abstract}
Аннотация
Общественный факт, что литературный перевод представляет собой разновидность литературного процесса, который сам становится началом новой литературной жизни и мышления, способствует развитию межкультурных коммуникаций, касается и перевода творчества грузинского поэта-романтика XIX в. Николоза Бараташвили (1817-1845) на разных языках; Переводы Н. Бараташвили не были изданы при жизни поэта. Процесе перевода его произведений особенно активизируется после 20-х гг. прошлого столетия. Бараташвили переводили на русский язык как грузинские, так и русские поэты и переводчики: В. Гаприндапшили, Б. Пастернак, Г. Цагарели, М. Дудин и др. Всесоюзный конкурс, объявленный в 1966 г., дал возможность поэтам и литературоведам разньх национальностей, опираясь на русский перевод, познакомить читателей с грузинским шедевром. Особенно значительны русские переводы Б. Пастернака, который старался при переводе быть предельно близким современному читателю.
\end{abstract}

Ключевые слова: Переводы Поэзии, Общественный Факт, Н. Бараташвили, Русский Перевод, Литературная Жизнь.

1. E-mail: Tamilagogoladze@gmail.com 


\section{Введение}

Общеизвестный факт, что литературный перевод представляет собой разновидность литературного процеса, способствует развитию межкультурных коммуникаций, даёт возможность интересоваться переводом с одного языка на другой и возможность для читателя быть близким к шедеврам мировой культуры. «Индивидуальное своеобразие авторской манеры, проявляющееся во всём творчестве писателя или в отдельном произведении, также как и национальное своеобразие литературы и его историческая окраска, не составляют какого-то отдельного формально выраженного элемента, а представляют собой сложную систему «взаимосвязанных и взаимопереплетающихся особенностей, затрагивающих всю ткань произведений и выражающуюся в языковых образах), отмечал А.В. Фёдоров (Фёдоров 1968. 337). И далее, особенное внимание уделял языку, так как «Всякая удача разрешаемая в переводе (идейно-познавательнаяприменительно к научной литературе, идейно-эстетическая - применительно к литературе художественной), разрешается только языковыми средствами» (Там же. 10).

Переводческая традиция в Грузии существует издавна (ещё с античного периода), но с принятием грузинским народом христианства, усиливается стремление к переводу Библии и Жития святых. Здесь и формируются законы переводческой деятельности (что и как переводить). (Гиорги Мтацминдели, Эфрем Мцирэ). В связи с политическими событиями грузины переводят с персидского и турецкого (но только художественную литературу).

В это время, в западной истории перевода формируются два принципа: дословный и свободный перевод. После распространения романтизма в Грузии (с начала XIX в.), литераторы, общественные деятели, наряду с персидским, турецким и греческим, овладевают и русским, немецким, французским языками (с I половины XIX в.). А с 60-х гг. XIX в. под руководством 
грузинского писателя и общественного деятеля Ильи Чавчавадзе (1837-1907), уже строго определяются принципы перевода.

К этому периоду творчество гениального грузинского поэта-романтика Николоза Бараташвили (1817-1845) было известно только в литературных салонах.

Потомок царя Ираклия II писал: «Ужасна была судьба Бараташвили. С самой ранней юности, придавленной тяжёлой жизнью, поэт, на первый взгляд, как будто примирился с горькой участью и погрузился в удручающие мелочи повседневного прозябания. Но нет, внутренний голос вновь и вновь звал его к подвигу. Он верил, что был призван служить возвышенной цели, чувствовал у себя могучие крылья, и знал, как высоко он мог взлететь. У него было лишь одно истинное убежище, где он мог целиком расскрыть свою душу и следовать внутреннему голосу без оглядки. Этим убежищем была поэзия. Здесь он был независим и свободен от окружающего лживого, беспощадного и жестокого мира... Он возвращался к природе и сливался с ней, как частица, некогда отторженная от целого... Бараташвили, как и современных ему романтиков запада, влечёт задумчивая тишина...» (Абашидзе 1968. 28-29).

В творчестве Бараташвили привлекает писателя зрелость философского мышления, возвышенный художественный стиль, простота языка. Отсюда и стремление к переводу на языки Российской империи (русский, азербайджанский, армянский и др.).

В данной статье мы старались определить, что привлекло в творчестве Н. Баратапвили читателя и какакя роль принадлежит ему в межкультурной коммуникации.

\section{Основная часть}

Поэзия Н. Бараташвили отличается своей, грузинской, совместно общечеловеческой художественной особенностью. Здесь почти отсутствуют 
восточные мотивы, характерные литературе XVII-XVIII вв. Она очень близка творчеству великих романтиков своего времени (Д. Байрону, М.Ю. Лермонтову) и поэтому нередко его называли поэтом принадлежащим «школе Байрона». Литераторы находили параллели с этими романтиками, возникшие независимо друг от друга на аналогичном социально-историческом фоне. Как отмечал исследователь Павле Ингороква (анализируя стихотворение Н. Бараташвили «Соловей и роза»), нигде, ни в старогрузинской, и вообще, в восточной поэзии: ни в иранской, ни в арабской, такая художественная разработка темы « Розы и соловья» не встречается.

Поэт-символист Валериан Гаприндашвили, который одним из первых переводил его стихотворения, писал: «Если представить себе поэзию как маскарад, Бараташвили будет самой траурной фигурой этого маскарада.

Бараташвили - Гамлет грузинской поэзии. Его стихотворения подобны монологам датского принца и сам он, как будто в маске Гамлета поёт свои стихи и произносит «быть или не быть»: Бараташвили первым из грузинских поэтов осмелился заглянуть в лицо своей думе - Медузе. И его поэзия странный и жуткий диалог между поэтом и его двойником» (Гаприндашвили 1922. 18)

Бараташвили - первый Дионис грузинской поэзии, в которой с исключительной силой воплощено безумие и оригинальность мечты, возжаждавшей чуда». (Там же.)

Валериан Гаприндашвили, как и многие поэты и прозаики, сам интересовался теорией перевода. Об этом свидетельствует незаконченная рукопись статьи «О переводе», где Гаприндашвили даёт краткий обзор истории переводческой традиции мировой литературы и предлагает новый подход - адекватный перевод, когда переводчик должен подробно изучить писателя и его эпоху, произведения сочинителей его направления или школы, взгляды его противников (как например Стендаля и Шатобриана, Шекспира и 
Бена Джонсона). Переводчик, по его мнению, не сможет достичь адекватности, если только преследует цель дословного точного перевода. Нужно, нередко и траспонировать, то есть внести те поправки, которые связаны с различиями между языками двух национальностей, эпохой, местными условиями, культурами, литературными традициями и социальными слоями общества. Плох тот перевод, заключает автор, в котором лёгкий юмор теряет свою естественность (Гаприндашвили 1990. 687).

Эти принципы перевода Гаприндашвили считает объязательными в эпоху символизма, где адекватный перевод даёт возможность достичь идейное и эмоционально-художественное восприятие читателем. Сам Гаприндашвили прекрасно владел русским языком, переводил А.С. Пушкина, В. Брюсова, А. Блока, В. Маяковского, С. Есенина, Н. Тихонова, П. Антокольского.

Но несмотря на теоретические принципи перевода, В. Гаприндашвили, его переводимый стих, очень тяжеловесен, нет созвучия с подлинником, а восприятие известного стихотворения Н. Бараташвили «Мерани», в его суждениях связывается с «Пьяным кораблем» Артура Рембо, в котором «Дионис празднует свою победу над здравым смыслом и неудержимо стремится вперёд к гибели и к нирване» (Гаприндашвили 1922. 19). Так оценивает грузинский поэт-символист феномен Бараташвили.

Русский перевод поэзии Н. Бараташвили Валериан Гаприндашвили публикует в 1922 г., наряду с изданием полного собрания сочинений поэта.

И начинаются разные переводы поэзии грузинского поэта на русский, армянский, азербайджанский языки.

Но особенно интересен один факт:

В 1966 г. к юбилею Н. Бараташвили был объявлен всесоюзный конкурс перевода стихотворения «Мерани». На конкурсе было представлено более 500 переводов. Тогда жюри объявило, что на просмотр было выбрано 159 опубликованных переводов, но самым интересым был тот факт, что поэты, 
переводчики вообще, для перевода на иностранные языки народов советских республик, использовали русские переводы. (Цибахашвили 2000. 38) (Нам не удалось установить первый источник. Не исключено, что могли быть и переводы В. Гаприндашвили).

В 70-е гг. ХХ столетия выходит всвет «Стихотворения. Поэма. Николоз Бараташвили» в переводе Михаила Дудина.

В начале книги печатается стихотворение М. Дудина с указанием автора.

Надпись на книге переводов
Николоза Баратаивили
Виднеетея новая веха
Холодная восходит заря.
Я с братом из прошлого века...
Сегодня встречаюсь не зря.
Поэзию пристальным взглядом
Он в душу мою устремлён
И судьбы становятся рядом
И нет между нами времён.

(Бараташвили 1972.6)

Кайсын Кулиев в предисловии переводов Дудина писал: «Известный советский поэт принадлежит к числу тех современных мастеров слова, которые придерживаются реалистических традиций русской класической поэзии... Дудин любит Кавказ, которому посвятил немало строк... Любовь и привязанность к Грузии и всему Кавказу, интерес к поэзии этой возвышенной земли побудил Дудина взяться за перевод стихов Бараташвили. Крупных поэтов неоднократно переводили заново, переводят и будут переводить. Несмотря на существование переводов Пастернака, Михаил Дудин решил по- 
своему. Как живут в русской поэзии переводы Пастернака, начнут жить и переводы Дудина» (Бараташвили 1972. 11-12)

На конкурсе перевода стихотворения «Мерани», особенно отличался перевод Бориса Пастернака. Сам Б. Пастернак, как поэт и переводчик, тоже интересуется с теоретическими принципами и собственного перевода: «Что сказать о принципах моих переводов? Величие подлинника избавляет меня от лишних объяснений. В отношении Шекспира уместны только совершенная естественность и полная умственная свобода. К первой я, как мы, готовимся в скромном ходе моих собственных трудов, ко второй подготовлен своими убеждениями («Заметки и переводе») (Мастерство перевода 1968. 106).

Но как отмечал теоретик перевода Г. Цибахашвили: несмотря на достоинства, он далёк от идеала. (Цибахашвили 2000. 38) Это и подчёркнуто в статье Вл. Огнева «У карты советской поэзии» (Заметки о переводе): Принцип перевода Б. Пастернака на том и основан, что главным для автора - сделать классика предельно близким современникам. И то, что поэтический образ мог быть собственностью его поэзии, для него уже достаточный повод применения этого образа в переводной ткани стиха. Такт большого художника чаще удерживал Пастернака в русле применения таких современных художественных средств, которые приближая к нам подлинник, делая его живым, понятным, продолжающим волновать нас, в то же самое время не разрушали бы могуществееную иллюзию перенесения читателя в ту эпоху, в которую он создавал.» (Мастерство перевода 1966, 1968. 287).

Далее исследователь Вл. Огнев, строя свои рассуждения о пастернаковском переводе, пишет: «Б. Пастернак там казался уязвымим, где рисунок образа или другие элементы, формы, весьма характерные для оригинальных стихов, оказывались в особом фокусе восприятия. Тут мы сразу чутвствовали некоторое насилие над первоисточником. Либо его модернизацию, либо чрезмерную «остроту» и сложность образа. 


$$
\begin{aligned}
& \text { О, взеляды, острые как ножсницы! } \\
& \text { Мы славим ваиу бессердечность } \\
& \text { Н жсизнь вам отдаем в золожницы, } \\
& \text { Чтоб выкупом нам стала вечность }
\end{aligned}
$$

Я думаю, Бараташвили не мог так «опредмеченно» сравнить и «взгляды с ножницами» (романтический канон позволил бы сравнение остроты взора с кинжалом!). Сегодня после пастернаковской поэзии не покажутся странными эти «ножницы», напротив, в сравнении больше жизненной убедительности, нежели в отвлеченном «кинжале». Женщина, даже оставляя за собой, на крайний случай, право общения с кинжалом, большей частью имеет дело ... с ножницами. Однако наш реалистический резон в применении к поэзии Бараташвили неуместен. И в этом вся суть. Принцип перевода Б. Пастернака на том и основан, что главное для автора сделать классика предельно близким современнику. И то, что поэтический образ мог быть в собственной его поэзии, для него уже достаточный повод применения этого образа в передовой ткани стиха» (Мастерство перевода 1968. 287-288).

Григол Абашидзе в своём докладе, прочитанном на торжественном заседании, посвящённом 150-летию со дня рождения великого грузинского поэта и мыслителя Николоза Бараташвили, 11 сентября, 1968 г., характеризуя «Мерани», пример приводит из переводов Б. Пастернака. Например:

\section{«Я к звездам неба в поддантство впишусь $)$}

«Пусть оторвусь я от семейных уз,

Мне все равно, где ночь в пути нагрянет,

Ночная даль моим ночлегом станет,

Я к звёздам неба в подданство впишусь».

(Бараташвили 1982.69). 
«Вперёд мой конь! Мою печаль и думу

Дыханием ветра встречного обвей».

(Абашидзе 1968. 32)

«Стрелой несется конь мечты моей.

В догонку ворон каркает угрюмо.

Вперёд мой конь! Мою печаль и думу

Дыханием ветра встречного обвей».

(Бараташвили 1982. 70)

В Грузии переводы Пастернака из Бараташвили считают классическими, так как здесь редкое сочетание стилевого, синтаксического, ритмического сплава с оригинальной формой стиха, «напоённой» интонациями грузинской речи», отмечает Вл. Огнёв (Мастерство перевода 1966, 1968. 289).

Переводы творчества произведений Н. Бараташвили были изданы в 1982 г. издательством «Мерани» с предисловием Григола Абашидзе.

В данной статье мы приводим сравнение трёх переводов стихотворения Н. Бараташвили «Мерани» - В. Гаприндашвили, Б. Пастернака, М. Дудина. Каждый перевод имеет свой отпечаток времени, принципа и стиля данной эпохи и эпохи переводимого произведения. Форматы данной статьи не дают возможность полностью проанализировать вышеупомянутые переводы на переводческом и литературоведческом уровнях, но одно можно отметить: они своеобразны, проникнуты стремлением переводчика представить читателю (в нашем случае, русскоязычному), понятным основной смысл и художественное достоинство оригинала, созданного в эпоху романтизма.

(Перевод В. Гаприндашвили)

\section{Мерани}

«Летит и мчит меня конь искрометный смело.

За мною ворон злой - его я узнаю! 
Скакун! Пусть твой полет не ведает предела

И думу черную отдает ветрам мою!

Сквозь бурю волн, грозу, по безднам и по скалам

Лети мой конь и мне путь жизни сократи

Лети в ненастие, в жару - под небом альми.

И не щади меня усталого в пути!

Сеериу в своих мечтах усединенных тризну

По родине, друзьям, к деве дорогой.

Где ночь или заря застигнет - там отчизну

Найду и посвяцу светилам вздох святой!

Стон сердиа - стон тоски морским доверить волнам!

Забыться в трепете твоем - безумья полном!

Лети мой конь, лети в невозвратимый путь

И дай душе в ветрах свободных потонуть.

И пусть не будуя оплакан девой милой.

И пусть земле родной мой прах не предадут.

Могилу выроет мне ворон чернокрыльий

И в своем ураган засыплет мой приют.

Не очи милье, меня оплачут росы,

И будут кориунь носиться вкруг с угрозой.

Лети, мой конь, лети и пронеси сквозь Рок.

Его рабом вовек не будет твой ездок! 


\footnotetext{
Пусть, где то там вдали, умру осиротельй.

Не дам торжествовать я Рока лезвию.

Лети, мой конь, лети, не ведая предела

И дуиу черную отдай ветрам мою.
}

\author{
Мучения души ведь не погибнут даром. \\ Как этот путь мой конь, непротоптанный тобой. \\ Грядуций мой собрат на поединке яром \\ Коня отважного промчит перед судьбой.
}

Летит мой конь вперед неудержимо, смело.

За мною ворон злой - его я узнаю.

Лети, скакун, лети, не ведая предела,

И дуиу черную отдай ветром мою!»

Перевод И. Гаприндашвили следует его же принципам адекватного перевода, но сам лирический герой отличается от героя Бараташвили. Потеряно слияние эмоционально-художественного воздействия с содержанием. Стих создан по слоговой системе $(13,11)$, отсутствует аллитерация, с этим связана и музыкальность. Основной акцент перенесён на образ лирического героя.

(Перевод Б. Пастернака)

$$
\text { Мерани }
$$

Стрелой несется конь мечты моей.

Вдогонку ворон каркает угрюмо.

Виеред, мой конь! Мою печаль и думу

Дьханьем ветра втречного обвей. 
Bnеред, вперед, не ведая преград,

Сквозь вихрь, и град, и снег, и непогоду,

Ты должен сохранить мне дни и годы.

Вперед, вперед, куда глаза глядят!

Пусть оторвусь я от семейныз уз.

Мне все равно, где ночь в пути нагрянет.

Ночная даль моим ночлегом станет.

Якзвездам неба в подданство впииусь.

Я вверюсь скачке бешеной твоей

И исповедаюсь морскому иуму.

Виеред, мой конь! Мою печаль и думу

Дьиханьем ветра встречного обвей

Пусть я не буду дома погребен.

Пусть не рыдает обо мне супруга.

Могилу ворон выроет, а вьюга

Завоет, возвраицаясь с похорон.

Крик беркутов заменит певчих хор

Роса небеснал меня оплачет.

Bперед! Я слаб, но ничего не значит,

Bnеред, мой конь! Вперед во весь опор

Я слаб, но я не раб судьбы своей.

Я с ней борюсь и замысел таю мой.

Вперед, мой конь! Мою печаль и думу

Дьханьем ветра встречного обвей. 


\author{
Пусть я умру, порыв не пропадет, \\ Ты протоптал свой след, мой конь крылатый, \\ И легче будет моему собрату \\ Пройти залной когда-нибудь вперед.
}

Стрелой несется конь мечты моей.

Вдогонку ворон каркает угрюмо.

Вперед, мой конь! Мою печаль и думу

Даханьем ветра втречного обвей.

В отличии от других переводов Б. Пастернак передаёт стремления лирического героя не в реальном (как в оригинале) а переносном - Мерани конь мечты моей. Этим сближает читателя с лирическим героем, отдаляя от подлинника. Здесь присутствует внутренняя музыкальность.

(Перевод М. Дудина)

Виереди бездорожье. Быстрее, Мерани!

Ворон каркнул. Скрываются горы в тумане,

Нет предела движенью. Мерани, развей!

Ветром беиеньм мрак моих мыслей развей

По горам и ущеелья над дикою яростью вод

Нетерпенье мое захлестии быстротою в пути.

Через холод и зной, через пропасть земных непогод.

Не щадя седока, обгоняя усталость, лети.

Я покинул отчизну, оставил друзей и родньхх.

Не увижу любимой и песни о ней не спою. 
Свой рассвет и закат повстречав на распутьях иных.

Только звездам поведаю тайну свою.

Только скорости бега и вольности моря

Я остаток любви раздарю, раззадоря

Bетер. Bетер, мрачные мысли развей!

Нет предела движенью. Мерани, резвей!

Пусть любимая слез не прольет надо мною в тоске.

Пусть мой прах не схоронят на старом отуовском погосте.

Ворон выроет яму в пустынном сыпучем песке

Вихрь ревущий засыплет мои одинокие кости.

Словно слезы любимой, роса упадет на меня.

Причитанья родньх мне заменит зловещая птица,

Так быстрее лети за предел уходящего дня.

Никогда твой хозяин с уделом своим не мирится.

Пусть умру одиноко, отвергнут судьбою,

Сталь врага навсегда презираема мною.

Нет предела движенью. Мерани, резвей!

Ветром беменьм мрак моих мыслей развей.

Не бесплодно стремление дуии обреченной в борьбе,

Пусть, пробитьй тобой, не исчезнет бесследно, как дьм.

Пусть собратьев моих, на извечную зависть судьбе,

Быстроногий скакун пронесет по дорогам крутыл. 


\author{
Виереди бездорожве. Быстрее, Мерани! \\ Ворон каракнул. Скрываются горы в тумане. \\ Нет предела движенью. Мерани резвей! \\ Ветром беменьмм мрак моих мыслей развей!
}

В переводе М. Дудина акцент перенесён на музыкальность стиха, но этого переводчик достигает при помощи повтора (развей, развей), все перенесено не на лирического героя, а на коня - Мерани.

Мы представили три перевода Н. Бараташвили «Мерани», который отличается особенной художественной силой в оригинале, как отмечают большинство грузинских литературоведов, «И здесь поражает нас дерзость мечты, казалось бы, навсегда побеждённого роком и пригвожденного к земле человека, поражает его безумство, его готовность преодолеть привратности судьбы, вписаться в подданства звездам, увидеть незримое... Он мчится за грань судьбы, чтобы не быть ее пленником. Ради этой цели и стоит пожерствовать собой, ведь за гранью судьбы бесконечность, начало свободы» (Абашидзе 1968. 32). Всё это мельком выявляется в переводах, но значение всех трех переводов своеобразно и значительно, даёт возможность читателю познать движение души поэта-романтика.

\title{
Зак.пючение
}

Грузинского поэта-романтика Николоза Бараташвили переводят спустя 50 лет после его смерти. Заинтересованность его произведениями исходит от стремления познать мир, душевный строй, характер и художественную особенность лучшего представителя романтического направления, который охватил почти весь цивилизованный мир в XIX в. Всесоюзный конкурс, объявленный в 1966 г., дал возможность поэтам и литературоведам разных национальностей, опираясь на русский перевод, познакомить читателей с грузинским шедевром «Мерани». 
Это даёт возможность достичь коммуникации между разными культурами, которые, не зная чужого языка, могут соприкасаться с творчеством. Но надо учесть и своеобразную «музыку», сохранить звукосмысловые ассоциации, которые находятся в глубине слов, которые надо угадать в подлиннике. Такое достигается только большим и абсолютным знанием языка переводимого подлинника и переводчика.

Мы разделяем взгляды известного писателя Владимира Набокова, прекрасного переводчика и теоретика перевода, который, характеризует истинного переводчика, как мастера: Здесь переводчику надобно быть не только человеком, прекрасно владевшим языком переводимого текста, но и понимавшим словообразование, фразеологизмы, традиции, нравы, исторические аллюзии и, самое главное, быть одарённым.

Переводы грузинского поэта, который жил полвека тому назад, сделаны с оригинала, требуют другого подхода. Поэтому, как мы предлагаем, все переводы, которые сделаны посредством перевода с другого языка, должны иметь историческое значение, должны быть проникнуты стремлением познать поэта другой национальности. Настало время истинно высокохудожественного перевода с подлинника.

\section{Литература}

1- Абашидзе Григол (1968). Николоз Баратамвили. Тбилиси, Изд-во «Ганатлеба», с. 28-29.

2- Бараташвили Н. (1922). Стихотворения. Поэма. Переводы и редакция Валериана Гаприндашвили, Тифлис, Изд-во «Государственное издательство». c. 18

3- Бараташвили Н. (1972). Стихотворения. Поэма. Перевод с грузинского М. Дудина, Тбилиси, Изд-во «Мерани», с. 6, 11-12.

4- Бараташвили Н. (1982). Стихотворения. Поэма. Перевод с грузинского Б. Пастернака, Тбилиси, Изд-во «Мерани». 
5- Гаприндапвили В.И. (1990). Стихи, поэмы, переводы, эссе, письма, материаль из архива (на грузинском языке), Тбилиси, Изд-во «Мерани», с. 687.

6- Мастерство перевода 1966 (1968). Москва, Изд-во «Советский писатель», с. 289.

7- Набоков В.В. (1998). Лекции по русской литературе, М., Изд-во «Азбука», с. 395

8- Фёдоров А.В. (1968). Основы общей теории перевода, Москва, Изд-во «Высшая пккола», с. 10, 373.

9- Цибахашвили Г. (2000). Вопросы теории и практики перевода (на грузинском языке), Тбилиси, Изд-во ТГУ, с. 38.

\section{Bibliography}

1- Abashidze Grigol (1968). Nikoloz Baratashvili. Tbilisi, Izd-vo «Ganatleba», s. 28-29.

2- Baratashvili N. (1922). Stihotvorenija. Pojema. Perevody i redakcija Valeriana Gaprindashvili, Tiflis, Izd-vo «Gosudarstvennoe izdatel'stvo». s. 18

3- Baratashvili N. (1972). Stihotvorenija. Pojema. Perevod s gruzinskogo M. Dudina, Tbilisi, Izd-vo «Merani», s. 6, 11-12.

4- Baratashvili N. (1982). Stihotvorenija. Pojema. Perevod s gruzinskogo B. Pasternaka, Tbilisi, Izd-vo «Merani».

5- Gaprindashvili V.I. (1990). Stihi, pojemy, perevody, jesse, pis'ma, materialy iz arhiva (na gruzinskom jazyke), Tbilisi, Izd-vo «Merani», s. 687.

6- Masterstvo perevoda 1966 (1968). Moskva, Izd-vo «Sovetskij pisatel'», s. 289.

7- Nabokov V.V. (1998). Lekcii po russkoj literature, M., Izd-vo «Azbuka», s. 395

8- Fjodorov A.V. (1968). Osnovy obshhej teorii perevoda, Moskva, Izd-vo «Vysshaja shkola», s. 10, 373 .

9- Cibahashvili G. (2000). Voprosy teorii i praktiki perevoda (na gruzinskom jazyke), Tbilisi, Izd-vo TGU, s. 38.

\section{HOW TO CITE THIS ARTICLE}

Gogoladze Tamar Akhmedionowna (2018). Translations of Georgian poet N. Baratashvili into Russian Language in the Aspect of Cross-Cultural Communication. Issledovatel'skiy zhurnal russkogo yazyka i literatury. 12(2): pp:11-28.

DOI: 10.29252 iarll.12.11

URL: http://journaliarll.ir/article-1-140-en.html

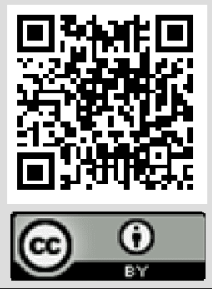




\title{
جكيدههاي فارسى
}

\section{بررسى ترجمه اشعار شاعر گرجستان، باراتاشويلى به زبان روسى از دريجهُ | ارتباطات فرهنكى}

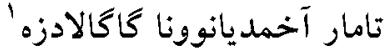

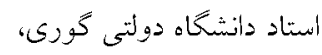 \\ كورى، كرجستان.

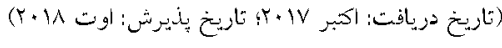

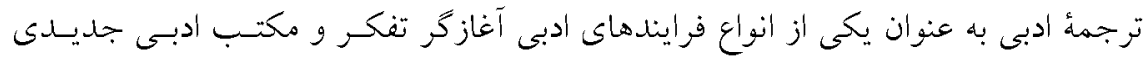

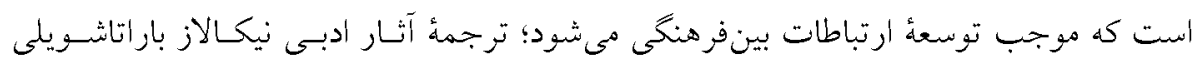

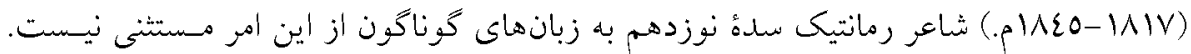

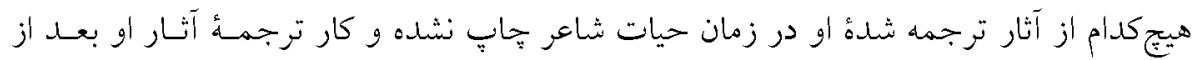

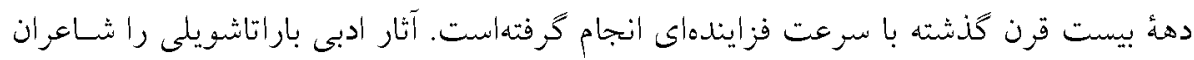

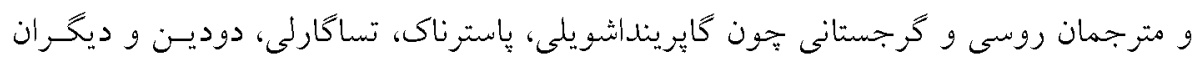

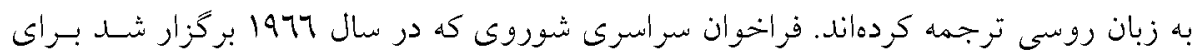

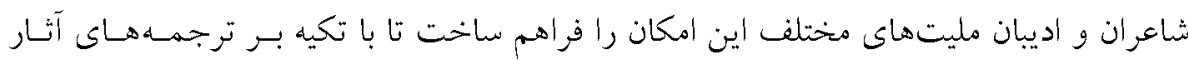

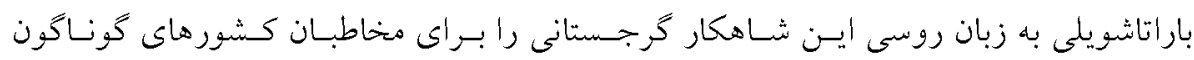

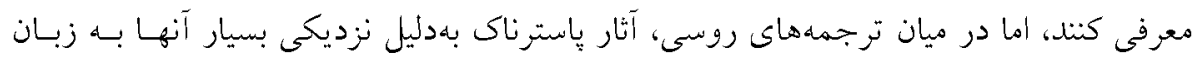
مخاطبان و خوانندكان معاصر اهميت ويزهاى داشتهاندان. وازگًان كليدى: ترجمة اشعار، واقعيت اجتماعى، باراتاشويلى، ترجمهُ روسى، زندكى ادبى. 